\title{
Anti-thrombotic Attribute of Different Type of Mushrooms
}

\author{
Rahul Mehta* \\ Dr. Rajendra Prasad Central Agriculture University, Pusa, Samastipur-848125, India \\ *Corresponding author
}

\section{A B S T R A C T}

Keywords

Mushroom, Antithrombotic,

G.lucidium,

A.auricula-judae,

P.giganteus

\section{Article Info}

Accepted:

10 July 2020

Available Online:

10 August 2020
Recent studies on Mushroom not only shows the importance of nutritive value but also medicinal properties of mushrooms. It produces different type of secondary metabolites which is found to boost our immunity by various biological activities. This review is done on the anti-thrombotic activity of different extract of mushrooms. G.lucidium, P.giganteus and Auricularia auricula-judae shows encouraging anti thrombotic activities. Blood coagulation plays serious roles in the incidences of cardiovascular problems. Achieving balance in human body between thrombus formation and destruction of it is very critical. This property of mushroom can be a substitute to treating cardiovascular diseases by traditional synthetic drug in future.

\section{Introduction}

Mushroom is a well-known fungus and is of great importance in modern era because of its use as diet supplement as well as its medicinal properties not only in India but all around the world.

The significant pharmacological effects and physiological properties of mushrooms are bioregulation (immune boost), maintenance of homeostas is and regulation of biorhythm, cure of various diseases and prevention and improvement from life menacing diseases such as cancer, cerebral stroke and heart diseases. Mushrooms are also known to have effective substances for antifungal, anti- inflammatory, anti-tumor, anti-viral, antibacterial, hepatoprotective, anti-diabetic, antithrombotic and hypotensive activities.

Thrombosis is the formation of a blood clot inside a blood vessel, obstructing the flow of blood through the circulatory system. When a blood vessel (a vein or an artery) is injured, the body uses platelets (thrombocytes) and fibrin to form a blood clot to prevent blood loss. Even when a blood vessel is not injured, blood clots may form in the body under certain conditions. A clot, or a piece of the clot, that breaks free and begins to travel around the body is known as an embolus. Blood coagulation plays serious roles in the incidences of cardiovascular problems. 
Achieving balance in human body between thrombus formation and destruction of it is very critical.

In this review, the anti-thrombotic capacities of some mushrooms have been discussed. Out of the thousands of mushroom species already identified, some species were reported as promising sources of anticoagulant compounds.

\section{Gandoderma lucidium Mushroom}

Ganoderma lucidum is a polypore mushroom belonging genus Ganoderma that grows as saprotrophs or parasites (3). It has been used for many years in Far East countries as a potent medicinal fungus (28). In Latin, the word lucidus means brilliant or shiny referring to the mushroom's fruiting body appearance which is varnished and sculptured (5). It is a dark large mushroom with a woody texture and glossy external surface, it has a kidney shaped cap giving it a distinct morphology. It is not classified as edible, due to their bitter taste also their fruiting bodies are so hard with no fleshy texture making it so hard to be eaten (16). Modern medicinal studies have demonstrated that this mushroom possesses a broad range of bioactivities, including anti-inflammatory, anti-oxidant, anti-glycemic, anti-ulcer, anti-cancer, and immune-stimulating effects. Hence, $G$. lucidum has been used to treat a variety of chronic diseases such as hepatopathy, nephritis, hypertension, arthritis, migraine, insomnia, bronchitis, asthma, diabetes and cancer $(7,14,19,21,26,34)$. Especially, it has also been recognized as an alternative adjuvant therapy for cancer and diabetes.

Ganoderma lucidum has been used as traditional medicinal herb to treat various disease for about 2000 years (17). It is found to be very useful for the treatment of various cardiovascular disorders. Ganoderma lucidum produces metalloprotease that exhibits both antithrombotic and fibrinolytic activities (8). The blood is clotting and lysis systems are highly regulated by several vital enzymes and any disturbance in these systems will results in life threating cardiovascular diseases. As it was known that blood clots are formed by thrombin from fibrinogen however, they are lyzed by plasmin that is activated from plasminogen by tissue plasminogen activator. A fibrin plate method assay was employed to test fibrinolytic protease of $G$. lucidum extract. A putative metalloprotease has been isolated from the mycelium of G. lucidum. The protease hydrolyzed human fibrin and fibrinogen as well as it showed a promising anticoagulant activity (8). This enzyme was found to be a $\mathrm{Zn} 2+$ metalloprotease as each mol of protease contains about $1.07 \mathrm{~mol}$ of $\mathrm{Zn} 2+$. The purified enzyme was able to hydrolyze the $\alpha$, and $\beta$ chain when incubated with human fibrinogen, however it did not affect $\gamma$ chain of fibrinogen. On the other hand, thrombin, hemoglobin, immunoglobulin and albumin are not affected by the presence of the protease enzyme under similar conditions (8). An anticoagulant activity using human plasma was also displayed by $G$. lucidum metalloprotease. The activated partial thromboplastin time (APTT) and thrombin time (TT) test in human plasma were used to evaluate the anticoagulant activity of the purified protease enzyme. As mentioned before APTT is employed to detect the coagulation defect in the intrinsic pathway, nevertheless TT assay is more sensitive to estimate the anticoagulant activity of the protease enzyme. The results showed that the prolonged TT could be related to the degradation of fibrin or fibrinogen. It was reported that the TT was prolonged by 2 and 3 times the control time at protease concentrations of 220 and $240 \mathrm{nM}$ respectively. However, the APTT required higher concentrations of the protease enzyme to reach 2 and 3 times the control value, 
where the protease concentrations were 1.1 and $2.2 \mu \mathrm{M}$ respectively (8).

Additionally, G. lucidum has a profound protective effect on the cardiovascular system since it is able to lower the blood cholesterol and triglyceride level as well as reduce the blood pressure. The clinical trials proved that two months administration of $G$. lucidum extract improved the blood pressure of hypertensive patients at the primary stage to reach normal blood pressure values (58). Another study reported that G. lucidum extract prevented the development of atherosclerosis in rats as it lowered blood lipid level (26).

Polysaccharides, one of the major bioactive compounds isolated from $G$. lucidum was found to improve many cardiovascular disorders such as chest pain and palpitation. Also it improves improvement in ECG in many cases, in addition to their hypotensive, antithrombotic and hypolipidemic activities (1). As a conclusion, G. lucidum is regarded as a effective medicinal herb showing variable biological activities including control some cardiovascular disease which is a global leading cause of death. Further clinical trials should be conducted to evaluate and confirm the safety and efficacy of G. lucidum natural products.

\section{Auricularia auricula-judae Mushroom}

Auricularia auricula-judae, the Jelly Ear Fungus, is mainly seen in winter and spring. It grows mainly on dead elder trees and on fallen branches, but occasionally you may also find it growing on other kinds of hardwood. The so-called Jelly Fungi are not really a taxonomic group but more a rag-tag of basidiomycetes with jelly-like textures, although few are a soft as the jelly we eat with custard. Many are capable of reconstituting and continuing to produce spores when wetted after desiccation. Fairly frequent in Britain and Ireland as well as in most countries of mainland Europe and parts of Asia and North America, the Jelly Ear fungus is seen mainly, but certainly not exclusively, on dead Elder wood in damp, shady locations. This fungus is also found in many parts of Asia and in Australia.

An acidic polysaccharide with anticoagulant activity was isolated from the edible mushroom Auricularia auricula using water, alkali or acid extracts. The alkali extract showed the highest anticoagulant activity and was thereby further purified using gel filtration chromatography. Specific anticoagulant activity of the purified polysaccharide was $2 \mathrm{IU} / \mathrm{mg}$ and its average mass was f $160 \mathrm{kDa}$. The polysaccharide from Auricularia auricula contains mainly mannose, glucose, glucuronic acid and xylose but no sulphate esters (33).

Auricularia auricula anti-thrombotic activity was due to catalysis of thrombin inhibition by antithrombin but not by heparin cofactor II. Inhibition of Factor Xa by antithrombin was not catalysed by the polysaccharide. The glucuronic acid residues were essential for the anticoagulant action of the mushroom polysaccharide since the activity disappeared after reduction of its carboxyl groups.

The polysaccharides from these mushrooms may constitute a new source of compounds with action on coagulation, platelet aggregation and, perhaps, on thrombosis (33).Therefore the edible mushroom Auricularia auricula may become a new source of antithrombotic compounds. Evaluation of Auricularia auricula polysaccharide as a novel alternative agent in thrombosis therapy requires further studies on characterization of its anticoagulant nature and the possible effect on experimental models of thrombosis (33) 


\section{Pleurotus giganteus}

P.giganteus (formerly known as Panus giganteus, Lentinus giganteus and Clitocybe maxima) domesticated in China and gaining popularity in Thailand and Malaysia. This mushroom is eaten by the indigenous communities of Malaysia. However, these communities do not attribute medicinal or wellness properties to this very popular culinary mushroom. In an effort to promote the consumers at large to add a new mushroom to their diets, the various medicinal properties of P.giganteus was explored $(23,30)$. The extracts of the freezedried fruit bodies of P.giganteus had fibrinolytic activity.

The specific activity of the top phase of the ATPS partial purification followed by acetone extraction was $157.9 \mathrm{U} / \mathrm{mg}$ protein. This was a 16 - fold increase in activity when compared to the crude extract. The estimated molecular weight was $35-45 \mathrm{kDa}$.

In conclusion all three mushrooms investigated had varying levels of fibrinolytic and anti-thrombiotic activities. The all three mushrooms-G. lucidium, P.giganteus and Auricularia auricula-judae can be incorporated into diets. These supplements of food can be helpful in treating very common cardiovascular disease in a natural way. Even currently, the main cause of death due to Covid 19 pandemic is due to inflammation of liver resulting in coagulation of blood in arteries, so it may replace the chemical drugs with more natural approach in future.

There is a need, however, to further study the daily requirements as well as relevant in vivo assays prior to recommendation for preventive and/or therapeutic uses in mitigating cardiovascular or respiratory tract complications caused by fibrin clots.

\section{References}

1. Ahmad MF. Ganoderma lucidum: Persuasive biologically active constituents and their health endorsement. Biomedicine \& Pharmacotherapy 2018; 107, 507-519.

2. AlshareefHJ, Aloufi OF, Aljohani NJ, Mirdad OA, Alghamdi BA,Alqattan HA. Anticoagulants: Their Adverse Effects and Reversal. Egyptian Journal of Hospital Medicine, 2018; 70(6). and left ventricular function in aged mice. International journal of biological macromolecules, 2010; 46: 284-288.

3. Arora D. Mushrooms demystified. Ed. Ten Speed Press. Berkeley, EUA 1986.

4. Bates ST. Arizona members of the Geastraceae and Lycoperdaceae (Basidiomycota, Fungi), Arizona State

5. Benzie IF, and Wachtel-Galor S. Herbal medicine: biomolecular and clinical aspects, CRC press 2011.

6. Biswas G, Nandi S, Kuila D, Acharya K. A comprehensive review on food and medicinal prospects of Astraeus hygrometricus. Pharmacognosy Journal, 2017; 9(6).

7. Chan WK; Cheung CC; Law HK; Lau YL; Chan GC Ganoderma lucidum polysaccharides can induce human monocytic leukemia cells into dendritic cells with immuno-stimulatory function. J. Hematol. Oncol, 2008, 21, 9.

8. Choi H.-S, and Sa Y.-S. Fibrinolytic and antithrombotic protease from Ganoderma lucidum. Mycologia2000; 92, 545-552.

9. Dulay RM, De Guzman ML, Magisa RR, Mariano JC, San Pedro MC, Mangansat. N. J, Peria JN. Philippine wild medicinal mushroom, Ganoderma lucidum (Curtis: Fr.) P. Karst., exhibits anticoagulative effect in intrinsic pathway. Advances in Environmental Biology, 2016; 10(4): 92 97.

10. Elkhateeb WA, Daba GM, Thomas PW, 
Wen TC. Medicinal mushrooms as a new source of natural therapeutic bioactive compounds. Egyptian Pharmaceutical Journal, 2019; 18(2): 88-101.

11. Evenson VS. Mushrooms of Colorado and the Southern Rocky Mountains. Big Earth Publishing, 1997.

12. Fares A. Winter cardiovascular diseases phenomenon. N. Am. Journal of Medical Science, 2013; 5: 266- 279

13. Harter K, Levine M, Henderson SO. Anticoagulation drug therapy: a review. Western Journal of Emergency Medicine, 2015; 16(1), p.11-17.

14. Ho YW; Yeung JS; Chiu PK; Tang WM; Lin ZB; Man RY; Lau CS Ganoderma lucidum polysaccharide peptide reduced the production of proinflammatory cytokines in activated rheumatoid synovial fibroblast. Mol. Cell. Biochem, 2007, 301, 173-179.

15. Holden L.Scotland's rare tooth fungi: an introduction to their identification, ecology, and management. Plant life International, 2008.

16. Jong S, and Birmingham J. Medicinal benefits of the mushroom Ganoderma. in Advances in applied microbiology, Elsevier. 1992; 101-134.

17. Jun T, and Ke-yan F. Experimental and clinical studies on inhibitory effect of Ganoderma lucidum on platelet aggregation. Journal of Tongji Medical University1990; 10, 240-243.

18. Khanna JM, Malone MH, Euler KL, Brady LR. Atromentin Anticoagulant from Hydnellum diabolus. Journal of pharmaceutical sciences, 1965; 54(7): 1016-1020.

19. Lee JM; Kwon H; Jeong H Inhibition of lipid peroxidation and oxidative DNA damage by Ganoderma lucidum. Phytother. Res, 2001, 15, 245-249.

20. Liu DZ, Liang HJ, Chen $\mathrm{CH}, \mathrm{Su} \mathrm{CH}$, Lee TH, Huang CT, Hou WC, Lin SY, Zhong WB, Lin PJ, Hung LF, Liang YC.
Comparative anti-inflammatory characterization of wild fruiting body, liquid-state fermentation, and solid-state culture of Taiwan fungus camphoratus in microglia and the mechanism of its action. Journal of Ethnopharmacology, 2007; 113: 45-53.

21. Ma H-T; Hsieh J-F; Chen S-T Antidiabetic effects of Ganoderma lucidum. Phytochemistry, 2015, 114, 109-113.

22. Moradali MF, Mostafavi H, Ghods S. and Hedjaroude GA. Immunomodulating and anticancer agents in the realm of macromycetes fungi (macrofungi). Int. Immunopharmacological, 2007; 101: 120-128.

23. Phan CW, Wong WL, Pamela D, Murali N, Vikineswary S. (2012). Pleurotus giganteus (Berk) Karunarathna \& K.D. Hyde: Nutritional value and in vitro neurite outgrowth activity rat pheochromocytoma cells. BMC Complementary and Alternative Medicine. 2012, 12:102 doi:10.1186/1472-6882-12-102

24. Rakhi K, Bhama SK, Surya K, Anila KN, Lakshmi R. A Review on Noval Anticoagulants. International Journal of Pharmaceutical and Clinical Research 2017; 9(1): 96-99.

25. Rickles F, and Falanga A. Molecular basis for the relationship between thrombosis and cancer. Thromb. Research, 2001; 102: 215-224.

26. Saltarelli R; Ceccaroli P; Iotti M; Zambonelli A; Buffalini M; Casadei L; Luciana Vallorani L; Stocchi V Biochemical characterisation and antioxidant activity of mycelium of Ganoderma lucidum from Central Italy. Food Chem, 2009, 116, 143-151. (Google Scholar) University Tempe 2004.

27. Wang GJ, Huang YJ, Chen DH, Lin YL. Ganoderma lucidum extract attenuates the proliferation of hepatic stellate cells 
by blocking the PDGF receptor. Phytotherapy Research: An International Journal Devoted to Pharmacological and Toxicological Evaluation of Natural Product Derivatives 2009; 23, 833-839.

28. Wasser SP.Medicinal mushrooms as a source of antitumor and immunomodulating polysaccharides. Applied Microbiology and Biotechnology, 2002; 60: 258-274.

29. Wasser SP. Reishi or ling zhi (Ganoderma lucidum). Encyclopedia of dietary supplements2005; 1, 603-622.

30. Wong WL, Mahmood Ameen A, Chua KH, Kuppusamy UR, Tan YS,Vikineswary S. Hepatoprotective effects of Panus giganteus (Berk.) Corner against thioacetamide (TAA)- induced liver injury in rats. Evidence based Complementary and Alternative Medicine,2012, doi:10.1155/2012/170303.

31. Wu Q, Tan Z, Liu H, Gao L, Wu S, Luo J, Zhang $\mathrm{W}$, Zhao $\mathrm{T}, \mathrm{Yu} \mathrm{J}, \mathrm{Xu} \mathrm{X}$. Chemical characterization of Auricularia auricula polysaccharides and its pharmacological effect on heart antioxidant enzyme activities.

32. Xie Y.-Z, Yang F, Tan W, Li X, Jiao C, Huang R, Yang BB. The anti-cancer components of Ganoderma lucidum possesses cardiovascular protective effect by regulating circular RNA expression. Oncoscience2016; 3, 203.

33. Yoon SJ, Yu MA, Pyun YR, Hwang JK, Chu DC, Juneja LR, Mourao PA. Nontoxic mushroom Auricularia auricula contains a polysaccharide with anticoagulant activity mediated by antithrombin. Thrombosis Research, 2003; 112: 151-158.

34. Yuen JW; Gohel MD The dual roles of Ganoderma antioxidants on urothelial cell DNA under carcinogenic attack. J. Ethnopharmacol, 2008, 118, 324-330.

35. YuJ, Sun R,ZhaoZ,Wang Y. Auricularia polytricha polysaccharides induce cell cycle arrest and apoptosis in human lung cancer A549 cells. International Journal of Biological Macromolecules, 2014; 68: $67-71$.

\section{How to cite this article:}

Rahul Mehta. 2020. Anti-thrombotic Attribute of Different Type of Mushrooms. Int.J.Curr.Microbiol.App.Sci. 9(08): 815-820. doi: https://doi.org/10.20546/ijcmas.2020.908.087 